Swarthmore College

Works

3-1-2005

\title{
Fitness Correlates Of Song Repertoire Size In Free-Living Song Sparrows (Melospiza Melodia)
}

\author{
J. M. Reid \\ P. Arcese
}

A. L. E. V. Cassidy

Sara Hiebert Burch

Swarthmore College, shieber1@swarthmore.edu

J. N.M. Smith

See next page for additional authors

Follow this and additional works at: https://works.swarthmore.edu/fac-biology

Part of the Biology Commons

Let us know how access to these works benefits you

\section{Recommended Citation}

J. M. Reid, P. Arcese, A. L. E. V. Cassidy, Sara Hiebert Burch, J. N.M. Smith, P. K. Stoddard, A. B. Marr, and L. F. Keller. (2005). "Fitness Correlates Of Song Repertoire Size In Free-Living Song Sparrows (Melospiza Melodia)". American Naturalist. Volume 165, Issue 3. 299-310. DOI: 10.1086/428299 https://works.swarthmore.edu/fac-biology/2

This work is brought to you for free by Swarthmore College Libraries' Works. It has been accepted for inclusion in Biology Faculty Works by an authorized administrator of Works. For more information, please contact myworks@swarthmore.edu. 


\section{Authors}

J. M. Reid, P. Arcese, A. L. E. V. Cassidy, Sara Hiebert Burch, J. N.M. Smith, P. K. Stoddard, A. B. Marr, and L. F. Keller 


\section{CHICAGO JOURNALS}

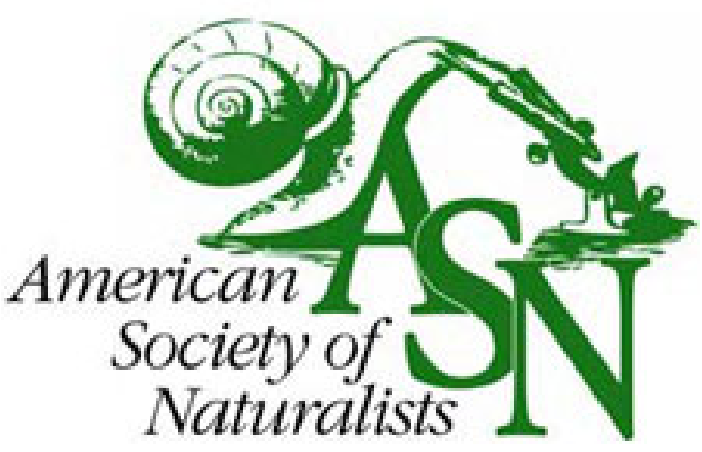

The University of Chicago

Fitness Correlates of Song Repertoire Size in Free-Living Song Sparrows ( Melospiza melodia) Author(s): Jane M. Reid, Peter Arcese, Alice L. E. V. Cassidy, Sara M. Hiebert, James N. M. Smith, Philip K. Stoddard, Amy B. Marr, and Lukas F. Keller Source: The American Naturalist, Vol. 165, No. 3 (March 2005), pp. 299-310

Published by: The University of Chicago Press for The American Society of Naturalists Stable URL: http://www.jstor.org/stable/10.1086/428299

Accessed: 05/03/2014 14:49

Your use of the JSTOR archive indicates your acceptance of the Terms \& Conditions of Use, available at http://www.jstor.org/page/info/about/policies/terms.jsp

JSTOR is a not-for-profit service that helps scholars, researchers, and students discover, use, and build upon a wide range of content in a trusted digital archive. We use information technology and tools to increase productivity and facilitate new forms of scholarship. For more information about JSTOR, please contact support@jstor.org. 


\title{
Fitness Correlates of Song Repertoire Size in Free-Living Song Sparrows (Melospiza melodia)
}

\author{
Jane M. Reid, ${ }^{1, \star}$ Peter Arcese, ${ }^{2, \dagger}$ Alice L. E. V. Cassidy, ${ }^{3, \downarrow}$ Sara M. Hiebert, ${ }^{4, \S}$ James N. M. Smith, ${ }^{3, \|}$ \\ Philip K. Stoddard, ${ }^{5, *}$ Amy B. Marr, ${ }^{2, * *}$ and Lukas F. Keller ${ }^{6,+\dagger}$
}

1. Department of Zoology, University of Cambridge, Downing Street, Cambridge CB2 3EJ, United Kingdom;

2. Centre for Applied Conservation Research, Forest Sciences, 2424 Main Mall, University of British Columbia, Vancouver, British Columbia V6T 1Z4, Canada;

3. Department of Zoology, 6270 University Boulevard, University of British Columbia, Vancouver, British Columbia V6T 1Z4, Canada;

4. Department of Biology, Swarthmore College, Swarthmore, Pennsylvania 19081;

5. Department of Biological Sciences, Florida International University, Miami, Florida 33199;

6. Zoologisches Museum, Universität Zürich, Winterthurerstrasse 190, 8057 Zürich, Switzerland

Submitted June 14, 2004; Accepted December 6, 2004; Electronically published January 20, 2005

ABstract: Models of sexual selection propose that exaggerated secondary sexual ornaments indicate a male's own fitness and the fitness of his offspring. These hypotheses have rarely been thoroughly tested in free-living individuals because overall fitness, as opposed to fitness components, is difficult to measure. We used 20 years of data from song sparrows (Melospiza melodia) inhabiting Mandarte Island, British Columbia, Canada, to test whether a male's song repertoire size, a secondary sexual trait, predicted overall measures of male or offspring fitness. Males with larger song repertoires contributed more independent and recruited offspring, and independent and recruited grandoffspring, to Mandarte's population. This was because these males lived longer and reared a greater proportion of hatched chicks

\footnotetext{
* Corresponding author; e-mail: j.reid@jesus.cam.ac.uk.

† E-mail: arcese@interchange.ubc.ca.

‡E-mail: alice.cassidy@ubc.ca.

s E-mail: shieber1@swarthmore.edu.

" E-mail: smith@zoology.ubc.ca.

*E-mail: stoddard@fiu.edu.

** E-mail: amarr@interchange.ubc.ca.

${ }^{\dagger \dagger}$ E-mail: 1fkeller@zoolmus.unizh.ch.
}

Am. Nat. 2005. Vol. 165, pp. 299-310. (C) 2005 by The University of Chicago. 0003-0147/2005/16503-40485\$15.00. All rights reserved. to independence from parental care, not because females mated to males with larger repertoires laid or hatched more eggs. Furthermore, independent offspring of males with larger repertoires were more likely to recruit and then to leave more grandoffspring than were offspring of males with small repertoires. Although we cannot distinguish whether observed fitness variation reflected genetic or environmental effects on males or their offspring, these data suggest that female song sparrows would gain immediate and intergenerational fitness benefits by pairing with males with large song repertoires.

Keywords: good genes, individual quality, lifetime reproductive success, secondary sexual ornament, sexual selection.

Females of many species use exaggerated secondary sexual male ornaments as cues for mate choice (Andersson 1994; Searcy and Yasukawa 1996; Kokko et al. 2003). However, the reasons why females prefer more ornamented males, and therefore the evolutionary mechanisms maintaining systems of intersexual selection, remain a matter of debate (Andersson 1994; Kokko et al. 2003). One possibility is that ornaments indicate a male's fitness (Andersson 1994; Kokko et al. 2003). Females could then benefit directly from choosing more ornamented males (Johnstone 1995; Kokko 1998; Møller and Jennions 2001). Furthermore, if fitness is heritable, females could additionally benefit by producing fitter offspring (Andersson 1994; Johnstone 1995; Kokko et al. 2003). These hypotheses make two major predictions concerning relationships between ornamentation and fitness: the degree of ornamentation should be positively correlated, first, with a male's own fitness and, second, with the fitness of his offspring.

Sexual selection models and empirical tests of their predictions have often focused on relating ornamentation to two specific fitness components: attractiveness and survival ("viability"; Andersson 1994; Kokko et al. 2002, 2003). Ornamentation has been shown to predict a male's own mating success and survival (Andersson 1994; GontardDanek and Møller 1999; Jennions et al. 2001; Evans 2003) and measures of attractiveness and viability in offspring (Møller and Alatalo 1999; Wedell and Tregenza 1999). Or- 
namentation can also predict a male's current and seasonal reproductive success (e.g., Catchpole 1986; Johnstone 1995; Wolfenbarger 1999). However, attractiveness, survival, and reproduction are costly life-history components that are subject to constraints and trade-offs imposed by allocation to each other and to other components such as growth (Gustafsson et al. 1995; Höglund and Sheldon 1998; Kokko et al. 2002). These components may therefore be negatively or positively correlated with each other and overall fitness (Kokko et al. 2002). Females choosing males for indirect (genetic) benefits should in fact select males with the greatest breeding value for fitness (measured as the mean fitness of offspring; Falconer and Mackay 1996; Hunt et al. 2004) irrespective of whether this is mediated by enhanced attractiveness, survival, or reproduction (Kokko et al. 2002, 2003). Few empirical studies, however, have investigated whether ornamentation indicates a male's overall fitness or that of his offspring rather than solely fitness components.

Measuring fitness is problematic (Falconer and Mackay 1996; Brommer et al. 2004). Even if the total number of offspring can be counted accurately, this census does not account for variation in offspring reproductive value. Since offspring quality and quantity may be negatively correlated, individuals that produce the most offspring may not, ultimately, leave the most descendants (Höglund and Sheldon 1998; Kokko et al. 2003). Fitness is therefore best estimated by measuring an individual's contribution to future generations (Houston and McNamara 1999; Brommer et al. 2004). Determining the number of grandoffspring produced or recruited is an achievable goal for empirical studies (Kokko et al. 2003; Hunt et al. 2004), although this still only approximates true fitness. While the necessary data are most practically collected in captive or laboratory populations, such artificial conditions may inaccurately indicate the relative fitness of phenotypes under natural conditions (e.g., Joron and Brakefield 2003). Fitness estimates from free-living populations are therefore particularly valuable but also suffer from uncertainty. Descendants may be overlooked because they emigrate from the study area, and parentage may be inaccurately assigned based on social behavior. These inaccuracies pose particular problems if they occur nonrandomly with respect to parental phenotype, thereby introducing bias into estimated relationships between phenotype and fitness. The likely magnitude and pattern of such bias must therefore be explicitly considered before reliable conclusions can be drawn. Furthermore, empirical relationships between ornamentation and male fitness may be confounded by covariation between male ornamentation and female quality or investment in offspring (Johnstone 1995; Sheldon 2000; Kokko et al. 2003). This problem is most convincingly minimized by experimentally enforcing random mating and reducing maternal effects by cross-fostering or artificial rearing (Johnstone 1995; Cunningham and Russell 2000; Sheldon 2000). However, such procedures are difficult within long-term studies of free-living individuals, and population-wide manipulations covering multiple generations have not yet been attempted. In the absence of these controls, the extent to which fitness variation reflects male quality rather than correlated female effects can be indicated by testing whether more ornamented males accrue success during life-history stages that are primarily affected by paternal rather than maternal investment (e.g., Hasselquist 1998).

We used a 20-year data set from free-living song sparrows (Melospiza melodia) inhabiting Mandarte Island, British Columbia, Canada, to investigate whether a male's song repertoire size predicted overall measures of male or offspring fitness. Song repertoire size is often cited as a classic example of an ornamental secondary sexual trait that is thought to influence female mate choice (Andersson 1994; Searcy and Yasukawa 1996). Male song sparrows sing complex repertoires consisting of between four and 13 distinct song types. Experimental and correlative evidence suggests that females preferentially mate with males with larger repertoires (Searcy and Marler 1981; Reid et al. 2004). We recorded song sparrow repertoire sizes on Mandarte during 1984-1993 (Hiebert et al. 1989; Cassidy 1993). The life histories of the recorded males and their offspring and grandoffspring have subsequently been described in detail (Keller 1998; Smith et al., forthcoming). We used these data to test whether a male's repertoire size predicted the total number of independent and recruited offspring, or independent and recruited grandoffspring, that he ultimately contributed to Mandarte's population. We also tested whether recruited offspring of males with larger repertoires themselves left more offspring and grandoffspring on average and whether relationships between paternal repertoire size and these fitness measures differed between sons and daughters. We consider whether emigration and extrapair fertilizations, which occur in this system, could have been sufficient and sufficiently biased to confound observed correlations between repertoire size and apparent fitness. Finally, we investigated whether fitness variation may be primarily attributable to male quality or correlated female investment by identifying the lifehistory stages at which males with large song repertoires accrued fitness advantages.

\section{Methods}

\section{Study Population}

Mandarte Island covers approximately 6 ha and lies 25 $\mathrm{km}$ northeast of Victoria, British Columbia, Canada. Its 
resident and relatively isolated song sparrow population has been studied intensively since 1975 (Arcese et al. 1992; Smith et al., forthcoming). During this time, virtually all nests have been located, and all sparrows hatched on the island have been marked with unique combinations of metal and color bands. Color-banded sparrows are easily observed across the whole island, and each individual's survival and reproduction has been documented accurately (Keller 1998; Smith et al., forthcoming). Although some independent juveniles do emigrate, emigration is thought to be relatively uncommon. Seven $(\sim 4 \%)$ of 186 juveniles reaching independence between 1982 and 1984 were located during thorough searches of neighboring small islands, two of which subsequently returned to Mandarte to breed (Arcese 1989). Further searches located seven $(\sim 1 \%)$ of 815 juveniles reaching independence between 1988 and 1995 (Keller 1998) but no further emigrants subsequently. Therefore, while other emigrants presumably went undetected (Koenig et al. 1996), available evidence suggests that emigration rates are low compared with the proportion of independent juveniles that recruit on Mandarte (32\% on average; Smith et al., forthcoming). No established breeders are known to have emigrated, and the disappearance of an adult from Mandarte is most likely to reflect mortality (Arcese 1989; Keller 1998).

\section{Life-History Data}

Each spring, all sparrows remaining on Mandarte were identified (Smith et al., forthcoming). Sexes were attributed based on behavior, and the territorial status of each male was noted (Arcese 1987; Smith et al., forthcoming). Each male's longevity and territory tenure (the total time for which territories were held) are therefore known to the nearest year. Since the probability of sighting a living individual on Mandarte is effectively 1, these observations provide unbiased estimates of local residence and survival (Keller 1998).

Song sparrows on Mandarte typically breed two or three times per season (Smith et al., forthcoming). They are primarily socially monogamous, although approximately a quarter of offspring are sired by extrapair males (K. D. O'Connor, A. B. Marr, P. Arcese, and L. F. Keller, unpublished manuscript). Females are entirely responsible for incubation (Arcese et al. 2002). Both parents provision chicks, but males often take primary responsibility for feeding fledged chicks while females lay and incubate another clutch (Arcese et al. 2002). During the study, nests were located during laying, incubation, or soon after chicks hatched. Laying date (the date of first egg) was recorded directly for nests found before clutch completion or backcalculated from hatch date or chick age for nests found subsequently. Clutch size was recorded directly for nests observed during incubation and was assumed to equal the number of chicks plus the number of unhatched eggs for nests located after hatching (Smith et al., forthcoming). The number of offspring hatching and reaching independence from parental care (between 24 and 30 days after hatching) was determined by intensively monitoring nests and color-banded fledglings. The identities of the individuals that recruited to Mandarte's breeding population, and their longevity and reproductive parameters, were subsequently recorded (Smith et al., forthcoming). The life histories of song sparrows breeding on Mandarte, and their offspring, have therefore been described in unusual detail (Arcese et al. 1992; Keller 1998; Smith et al., forthcoming).

\section{Song Repertoire Size}

Song sparrows regard song types as natural categories that transcend variations within these types (Stoddard et al. 1988; Searcy et al. 1999). Repertoire size (the total number of distinct song types) is therefore a biologically relevant measure of song complexity in this species. Song sparrows are "age-limited" learners; a male's repertoire is crystallized during his first winter and does not change subsequently (Searcy et al. 1985; Hiebert et al. 1989; Cassidy 1993; Nordby et al. 2002). During 1984-1985 and 1988-1993, we recorded song repertoire sizes of 54 male song sparrows on Mandarte that represented 13 birth cohorts (19801992). Since documenting repertoire size is time consuming, most individuals were recorded only once during their lives. For each individual, sufficient songs were analyzed to ensure that repertoire size was documented with high confidence. In 1984 and 1985, Hiebert et al. (1989) recorded a minimum of $3 \mathrm{~h}$ of continuous song per individual and in practice described no new song types after the first $90 \mathrm{~min}$. Subsequently, Cassidy (1993) analyzed a minimum of 210 continuous songs per individual (sufficient to document repertoire size with $95 \%$ confidence on Mandarte; Cassidy 1993). In most cases, the number of songs analyzed greatly exceeded this threshold (median 260 , maximum 2,558; 225 songs are sufficient to document repertoire size with 99\% confidence; Cassidy 1993). Recording and analysis procedures are described in further detail by Hiebert et al. (1989), Cassidy (1993), and Reid et al. (2004). The 54 recorded males and their offspring were no longer alive on Mandarte by 2003.

\section{Analysis}

We used general linear mixed models to test whether a male's song repertoire size predicted measures of male or offspring fitness or performance during specific components of a male's life history. We used the total number of grandoffspring reaching independence and recruiting 
on Mandarte as our main fitness measures (Kokko et al. 2003; Hunt et al. 2004). To aid comparison with other studies, we also examined the number of offspring reaching independence and recruiting. When relating paternal repertoire size to offspring fitness, we focused on data from locally recruited offspring. This approach eliminated error due to any independent offspring that recruited away from Mandarte and, since offspring sex was typically unknown until recruitment, allowed us to test whether relationships between paternal repertoire size and offspring fitness differed between sons and daughters. Similarly, we related repertoire size to a male's performance during specific lifehistory stages (listed and defined in table 1). Since many males bred multiple times and left multiple offspring, we included male identity as a random factor in analyses relating a male's repertoire size to his reproductive performance per breeding attempt and per season and relating paternal repertoire size to offspring fitness. We included male age, female age, laying date, and their respective quadratic terms as covariates in analyses of performance per attempt and per season. Genetic data are not available to verify the paternity of all sparrows sired during the longterm study. Consequently, we assumed throughout the analyses that a male's apparent (social) reproductive success reflected his true genetic fitness. We consider the validity of this assumption and the consequences of possible violations in "Discussion."

The 54 males whose song repertoire sizes were recorded hatched between 1980 and 1992 and bred between 1981 and 1998. Survival, reproductive success, and recruitment varied markedly on Mandarte during this time (Arcese et al. 1992; Smith et al., forthcoming). We therefore corrected for year and cohort variation in fitness and life-history variables. We included year as a random factor in analyses relating repertoire size to performance per season and attempt. In analyses of lifetime performance (e.g., longevity, lifetime reproduction), we adopted the standard approach of dividing each individual's observed performance by the mean performance of their cohort and related repertoire size to the resulting relative fitness estimates (Brodie et al. 1995; Falconer and Mackay 1996). We could not objectively calculate the relative performance of one male who was the only member of his cohort to survive through a population bottleneck in 1989 (Smith et al., forthcoming). We therefore excluded this male from analyses.

Since we related repertoire size to multiple fitness and life-history variables, we corrected $\alpha$ values to reduce the chance of wrongly rejecting a null hypothesis. We first calculated full Bonferroni corrections $\left(\alpha^{\prime}=\alpha / n\right.$, where $n$ is the number of tests; Sokal and Rohlf 1995). However, because this correction may be too conservative when tests involve correlated variables (Perneger 1998), we also calculated a reduced correction, accounting for the mean Spearman correlation between each set of related variables (http://home.clara.net/sisa).

While relationships between repertoire size and fitness measures could not be investigated without standardizing for temporal variation, the absolute magnitude of fitness variation is difficult to discern from relative fitness scores. We therefore used final models to estimate key fitness parameters for males with small, median, and large repertoires (five to six, eight, and 10-11 songs, respectively) and for recruited offspring of these males. These categories correspond to the extreme and median repertoire sizes that we observed and were chosen simply to indicate the degree of fitness variation occurring across this phenotypic range. To facilitate comparison with previous studies, we present Pearson product-moment correlation coefficients $(r)$ as a measure of effect size for relationships between repertoire size and male and offspring fitness (Møller and Alatalo 1999; Jennions et al. 2001). To indicate the strength of directional selection on repertoire size, we also present the regression coefficient $(B)$ for relationships between male repertoire size and relative fitness measures (the selection gradient; Falconer and Mackay 1996). To account for unequal sample sizes, proportional data were transformed by $2(n) \arcsin (q)$, where $q$ is the proportion and $n$ is the sample size (Draper and Smith 1981). Variables were excluded

Table 1: Components of a male's life history that were related to song repertoire size

\begin{tabular}{lll}
\hline Component & \multicolumn{1}{c}{ Definition } & \multicolumn{1}{c}{ Timescale } \\
\hline Longevity & Total years from birth to disappearance & Lifetime \\
Territory tenure & Total years spent defending a territory & Lifetime \\
Total breeding attempts & Total number of clutches laid by male's mates & Lifetime \\
Total eggs & Total number of eggs laid by male's mates & Lifetime \\
Seasonal laying date & Date of first egg each spring & Season \\
Breeding attempts per season & Number of clutches fathered per year & Season \\
Clutch size & Eggs per clutch & Breeding attempt \\
Hatching success & Proportion of eggs hatched per clutch & Breeding attempt \\
Rearing success & Proportion of hatched chicks reaching independence & Breeding attempt \\
Recruiting success & Proportion of independent young recruited on Mandarte & Breeding attempt \\
\hline
\end{tabular}



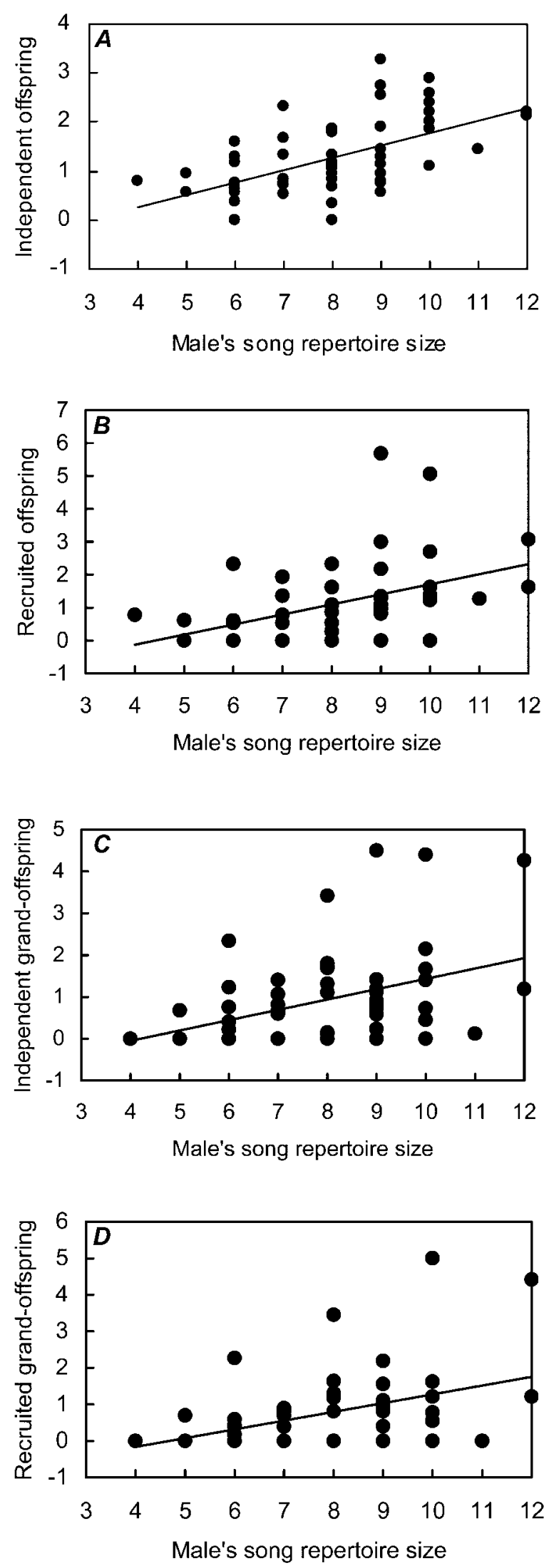

from models by sequential backward elimination if $P>$ .1. Statistics for eliminated variables were calculated by reintroducing each variable to the final model. Residuals did not deviate substantially from normality. Correlations between independent variables did not exceed $r=0.35$. All tests were two tailed. Analyses were carried out in SPSS 10.0 and Genstat 4.5.

\section{Results}

Across 54 song sparrows recorded during 1984-1993, song repertoire size averaged $7.9 \pm 1.8$ (mean $\pm 1 \mathrm{SD}$, range 4-12, coefficient of variation [CV] 22.6\%). Repertoire size did not differ among cohorts (one-way ANOVA, $F=$ $1.1, \mathrm{df}=12,41, P=.36$ ). Consistent with previous studies showing that song repertoires do not change with age in song sparrows (e.g., Cassidy 1993; Nordby et al. 2002), repertoire size did not vary with a male's age at recording $(r=0.22, N=54, P=.11)$.

\section{Repertoire Size and Male Fitness}

Across 53 males whose total reproductive success could be measured relative to cohort means, males with larger song repertoires left significantly more independent and recruited offspring and grandoffspring on Mandarte (fig. 1). We next identified the life-history stages at which males with large repertoires accrued this apparent fitness advantage. Males with larger repertoires lived longer and held territories for more years than males with smaller repertoires (table 2). The correlation between repertoire size and territory tenure remained significant after controlling for longevity (partial correlation, $P=.032$ ). The date on which laying commenced each season varied among years and with female age (table 3). Overall, males with larger repertoires tended to commence breeding earlier $(F=$ $3.3 \mathrm{df}=1,114, P=.07$ assuming no interaction with male age). However, there was a significant interaction between repertoire size and male age (table 3). First-year males with larger repertoires bred earlier $(N=32$ from

Figure 1: Relationships between a male song sparrow's song repertoire size and relative fitness measures: $(A)$ total offspring raised to independence, $(B)$ total offspring recruited on Mandarte, $(C)$ total independent grandoffspring, and $(D)$ total grandoffspring recruited on Mandarte. Across 53 individuals, males with larger repertoires left more independent and locally recruited offspring $(r=0.57, B=0.25, P<.001$ and $r=$ $0.45, B=0.31, P=.001$, respectively) and independent and locally recruited grandoffspring $(r=0.38, B=0.25, P=.005$ and $r=0.39$, $B=0.24, P=.004$, respectively). All four relationships were significant after applying a full Bonferroni correction (four tests, $\alpha^{\prime}=0.013$ ) and a reduced correction accounting for the mean Spearman correlation among the four fitness measures $\left(r_{\mathrm{s}}=0.67, \alpha^{\prime}=0.031\right)$. 
Table 2: Relationships between a male song sparrow's song repertoire size and components of his overall life history

\begin{tabular}{lccr}
\hline & \multicolumn{3}{c}{$\begin{array}{c}\text { Correlation with male's } \\
\text { song repertoire size }\end{array}$} \\
\cline { 2 - 4 } Life-history component & $r$ & $B$ & \multicolumn{1}{c}{$P$} \\
\hline Longevity & .43 & .12 & .001 \\
Territory tenure & .49 & .15 & $<.001$ \\
Total breeding attempts & .44 & .16 & .001 \\
Total eggs & .41 & .14 & .002 \\
\hline
\end{tabular}

Note: Relative longevity, territory tenure, total breeding attempts, and total eggs increased with repertoire size $(N=53$ males). Relationships were significant after applying a full Bonferroni correction (four tests, $\alpha^{\prime}=0.013$ ) and a reduced correction (mean Spearman correlation among four measures of lifetime performance, $r_{\mathrm{s}}=0.87, \alpha^{\prime}=0.042$ ). All eight tests of lifetime performance (fig. 1; table 2) remained significant after applying full (eight tests, $\left.\alpha^{\prime}=0.006\right)$ and reduced corrections (mean spearman correlation $\left.r_{\mathrm{s}}=0.55, \alpha^{\prime}=0.019\right)$.

10 cohorts, $F=9.2$, df $=1,19, P=.007$; see also Reid et al. 2004), while repertoire size did not predict laying date in older males $(N=103$ from 17 cohorts, $F=0.4$, $\mathrm{df}=1,82, P=.52$ ). Across all seasons, males with larger repertoires bred more times per season (table 3 ). However, potentially confounding effects of female age and laying date could not be included in this analysis because these variables were not quantifiable for seasons in which males did not breed. When these null seasons were excluded, the number of breeding attempts varied with laying date but not male repertoire size (table 3 ). However, males with larger repertoires bred more times in total (table 2). Females mated to males with larger repertoires did not lay larger clutches; clutch size instead varied with female age and laying date (table 3 ). However, males with larger repertoires fathered more eggs in total (table 2). The correlations between a male's repertoire size and his total breeding attempts and eggs were no longer significant after controlling for longevity (partial correlations, $P>.30$ ). Males with larger repertoires therefore bred more times and fathered more eggs because they lived longer.

The correlations between repertoire size and total reproductive success (fig. 1) remained significant after controlling for each male's total number of breeding attempts and eggs (partial correlations, $P<.01$ in all cases). This suggests that males with larger repertoires left more descendants partly because they achieved greater success per attempt rather than solely because they lived longer and made more attempts. Hatching success varied with laying date and female age but did not increase with male repertoire size (table 3). However, males with larger repertoires reared a greater proportion of hatched chicks to independence (table 3). Furthermore, independent off- spring of males with larger repertoires were more likely to recruit to Mandarte's breeding population, although this relationship was no longer statistically significant after $\alpha$ was corrected for multiple tests (table 3 ).

\section{Male Repertoire Size and Offspring Fitness}

Recruited offspring of males with larger song repertoires tended to leave more descendants on Mandarte than recruited offspring of males with smaller repertoires, particularly grandoffspring (table 4). The interaction between paternal repertoire size and offspring sex tended toward statistical significance for the number of recruited grandoffspring but not otherwise (table 4). Further investigation showed that sons of males with larger repertoires left significantly more independent and recruited grandoffspring than did sons of males with smaller repertoires but that these relationships were not significant for daughters (table 4).

On average, males with small repertoires (five to six songs) lived roughly $60 \%$ as long as males with large repertoires (10-11 songs) and left $25 \%-35 \%$ of the descendants (table 5). Recruited offspring of males with small repertoires lived roughly $85 \%$ as long as recruited offspring of males with large repertoires and left $30 \%-75 \%$ of the descendants (table 5). Estimated effect sizes $(r)$ for relationships between repertoire size and measures of male fitness generally exceeded those for relationships between repertoire size and measures of offspring fitness (fig. 1; tables 2, 4).

\section{Discussion}

Models of intersexual selection propose that secondary sexual ornaments indicate a male's own fitness and the fitness of his offspring (Andersson 1994; Kokko et al. 2002, 2003). However, few empirical studies have related ornamentation to measures of overall fitness as opposed to fitness components (Johnstone 1995; Kokko et al. 2003; Hunt et al. 2004). Although experimental manipulations are required to distinguish genetic and environmental effects on ornamentation and fitness, correlative data from free-living populations are valuable in quantifying the overall magnitude and direction of relationships between these traits (Møller and Alatalo 1999; Jennions et al. 2001).

On Mandarte Island, male song sparrows varied considerably in song repertoire size, a secondary sexual trait $(\mathrm{CV}=22.6 \%$, exceeding the degree of variation observed for other ornamental traits in birds; Møller and Alatalo 1999). Our analyses of detailed life-history data suggested that males with larger repertoires contributed more independent and recruited offspring, and independent and recruited grandoffspring, to the local population. This sup- 
Table 3: Relationships between a male song sparrow's song repertoire size and components of reproductive performance per season and per breeding attempt

\begin{tabular}{|c|c|c|c|c|c|c|c|c|c|c|c|c|c|c|c|c|c|c|c|c|c|}
\hline & \multirow{2}{*}{$\begin{array}{c}N_{\text {obs }} \\
\left(N_{\text {males }}\right) \\
\end{array}$} & \multicolumn{2}{|c|}{ Repertoire size } & \multicolumn{2}{|c|}{ Male age } & \multicolumn{2}{|c|}{ Male age $^{2}$} & \multicolumn{2}{|c|}{ Female age } & \multicolumn{2}{|c|}{ Female age $^{2}$} & \multicolumn{2}{|c|}{ Lay date } & \multicolumn{2}{|c|}{ Lay date ${ }^{2}$} & \multicolumn{2}{|c|}{$\begin{array}{l}\text { Male age } \times \\
\text { repertoire }\end{array}$} & \multicolumn{2}{|c|}{$\begin{array}{c}\text { Year } \\
\text { (factor) }\end{array}$} & \multicolumn{2}{|c|}{$\begin{array}{c}\text { Male } \\
\text { (factor) }\end{array}$} \\
\hline & & $F$ & $P$ & $F$ & $P$ & $F$ & $P$ & $F$ & $P$ & $F$ & $P$ & $F$ & $P$ & $F$ & $P$ & $F$ & $P$ & $F$ & $P$ & $F$ & $P$ \\
\hline \multicolumn{22}{|l|}{ Season: } \\
\hline Seasonal laying date & $135(50)$ & 7.2 & .009 & 2.1 & .15 & .7 & .39 & 19.2 & $<.001$ & 14.4 & $<.001$ & $\ldots$ & $\ldots$ & $\ldots$ & $\ldots$ & 4.2 & .041 & 8.2 & $<.001$ & 1.1 & .36 \\
\hline $\begin{array}{l}\text { Attempts per season } \\
\quad \text { (all seasons) }\end{array}$ & $168(53)$ & 5.1 & .026 & 1.9 & .17 & 1.5 & .22 & $\ldots$ & $\cdots$ & $\ldots$ & $\cdots$ & $\cdots$ & $\cdots$ & $\ldots$ & $\ldots$ & & & 1.1 & .35 & .9 & .68 \\
\hline $\begin{array}{l}\text { Attempts per season } \\
\text { (when breeding } \\
\text { attempted) }\end{array}$ & $142(50)$ & .3 & .57 & .5 & .48 & .4 & .51 & .2 & .66 & .2 & .65 & 23.3 & $<.001$ & .5 & .49 & & & 1.2 & .24 & 1.0 & .38 \\
\hline \multicolumn{22}{|l|}{ Breeding attempt: } \\
\hline Clutch size & $342(50)$ & 1.2 & .28 & .7 & .41 & .5 & .48 & 7.0 & .009 & 5.3 & .022 & 16.7 & $<.001$ & 24.9 & $<.001$ & & & 5.0 & $<.001$ & 1.4 & .08 \\
\hline Hatching success & $342(50)$ & .3 & .62 & 2.3 & .13 & .1 & .76 & 3.1 & .08 & 5.6 & .018 & 3.6 & .058 & 1.1 & .31 & & & 3.0 & $<.001$ & 1.2 & .20 \\
\hline Rearing success & $267(50)$ & 6.9 & .009 & 3.2 & .08 & 2.6 & .11 & .01 & .99 & .1 & .74 & 3.8 & .053 & 4.7 & .03 & & & 3.0 & $<.001$ & 1.1 & .28 \\
\hline Recruiting success & $201(50)$ & 4.1 & .045 & .03 & .86 & .01 & .96 & .2 & .69 & .01 & .91 & 8.5 & .004 & 1.0 & .32 & & & 3.6 & $<.001$ & 1.2 & .10 \\
\hline
\end{tabular}

Note: Variables retained in final models are indicated in bold. Interaction terms were not significant except where shown. $N_{\mathrm{obs}}$ and $N_{\text {males }}$ indicate sample sizes of observations and individual males, respectively. Sample sizes vary among analyses because not all males whose song was recorded bred or bred successfully every season, and three never bred. Corrected $\alpha$ values for three tests of seasonal performance and four tests of breeding success per attempt are 0.017 and 0.013 , respectively, applying a full Bonferroni correction and $r_{\mathrm{s}}=0.57, \alpha^{\prime}=0.031$ and $r_{\mathrm{s}}=0.08, \alpha^{\prime}=0.014$, respectively, accounting for the mean Spearman correlation among each set of variables. 
Table 4: Relationships between a male song sparrow's song repertoire size and the relative longevity and number of independent and recruited offspring and grandoffspring left by the male's recruited offspring

\begin{tabular}{|c|c|c|c|c|c|c|c|c|c|c|}
\hline \multirow[b]{2}{*}{ Measure of offspring fitness } & \multicolumn{4}{|c|}{$\begin{array}{l}\text { Father's song } \\
\text { repertoire size }\end{array}$} & \multicolumn{2}{|c|}{$\begin{array}{c}\text { Offspring } \\
\text { sex } \\
\end{array}$} & \multicolumn{2}{|c|}{$\begin{array}{l}\text { Interaction (father's } \\
\text { repertoire by } \\
\text { offspring sex) } \\
\end{array}$} & \multirow{2}{*}{$\begin{array}{l}\text { Effect size } \\
\text { for sons } \\
r\end{array}$} & \multirow{2}{*}{$\begin{array}{c}\begin{array}{c}\text { Effect size for } \\
\text { daughters }\end{array} \\
r\end{array}$} \\
\hline & $F$ & $P$ & $r$ & $B$ & $F$ & $P$ & $F$ & $P$ & & \\
\hline Longevity & 2.1 & .15 & .13 & .04 & 3.1 & .08 & $<.1$ & .85 & .15 & .11 \\
\hline Independent offspring & 2.3 & .13 & .13 & .06 & .2 & .64 & $<.1$ & .88 & .12 & .14 \\
\hline Recruited offspring & 3.8 & .05 & .16 & .10 & .3 & .60 & .1 & .78 & .15 & .18 \\
\hline Independent grandoffspring & 5.1 & .03 & .19 & .11 & 1.1 & .30 & 1.2 & .28 & $.26^{*}$ & .13 \\
\hline Recruited grandoffspring & 7.1 & .01 & .23 & .22 & 2.9 & .09 & 3.5 & .06 & $.35^{\star *}$ & .07 \\
\hline
\end{tabular}

Note: Paternal identity did not explain a significant proportion of variation in offspring performance $(P>.1$ in all cases). Offspring longevity and all four measures of total reproductive success tended to increase with paternal repertoire size. Relationships with the number of recruited and independent grandoffspring were statistically significant after applying a full Bonferroni correction (five tests, $\alpha^{\prime}=0.010$ ) and a reduced correction (mean Spearman correlation among five variables, $r_{\mathrm{s}}=0.66, \alpha^{\prime}=0.028$ ). Analyses used 134 recruited offspring of 39 males whose song repertoires were recorded, comprising 68 sons and 66 daughters (the remaining 14 recorded males left no recruited offspring).

${ }^{*} P<.05$.

** $P<.01$.

ports Hiebert et al.'s (1989) conclusion, based on 16 song sparrows on Mandarte, that males with larger repertoires leave more independent offspring. However, two possible biases must be considered before we can conclude that repertoire size indicates male fitness.

First, although Mandarte's song sparrow population is relatively isolated (Smith et al., forthcoming), some independent juveniles do emigrate (Arcese 1989; Keller 1998). While this emigration does not affect censuses of offspring reaching independence, our counts of recruits (and therefore grandoffspring) include only individuals that recruited on Mandarte. However, even the maximum possible bias in juvenile dispersal is unlikely to have been sufficient to negate our conclusion that males with larger repertoires left more recruits. Under average conditions, males with large repertoires (10-11 songs) left 4.5 recruits from 11.8 independent offspring on Mandarte compared with 1.1 recruits from 4.0 independents for males with small repertoires (five to six songs; table 5). All remaining independent offspring of males with small repertoires would therefore have to recruit elsewhere to approximately eliminate this difference, assuming also that none of the (considerably greater) number of independent offspring of males with large repertoires emigrated. Furthermore, individuals that emigrate may frequently fail to breed successfully elsewhere (Arcese 1989), and breeding success averages higher on Mandarte than in several surrounding populations (Zanette et al. 2003; S. D. Wilson and P. Arcese, unpublished manuscript). Reproduction away from Mandarte is therefore unlikely to have been sufficient, and sufficiently biased, to eliminate the observed difference in grandoffspring production between males with large and small repertoires.

Second, our analyses used counts of a male's social off- spring. Since extrapair fertilizations occur on Mandarte (K. D. O'Connor, A. B. Marr, P. Arcese, and L. F. Keller, unpublished manuscript), these counts may inaccurately reflect a male's true (genetic) fitness. Males with large repertoires would have had to lose a third of their paternity to males with small repertoires to eliminate the observed difference in production of independent offspring between males with large and small repertoires (table 5). This exceeds the average extrapair paternity rate observed in song sparrows on Mandarte and in a separate population in Washington State $(27 \%$ and $24 \%$, respectively; K. D. O'Connor, A. B. Marr, P. Arcese, and L. F. Keller, unpublished manuscript; C. E. Hill, S. E. Campbell, and M. D. Beecher, unpublished manuscript), although these averages suggest that a rate exceeding $30 \%$ is conceivable. It remains to be investigated whether extrapair paternity rates are biased with respect to song on Mandarte. However, a bias in favor of males with small repertoires would contradict patterns observed elsewhere. In song sparrows in Washington State, repertoire size did not significantly predict extrapair paternity or cuckoldry rates; the weak tendency was for males with larger repertoires to gain rather than lose paternity (C. E. Hill, S. E. Campbell, and M. D. Beecher, unpublished manuscript). In other passerines, males with larger repertoires and more ornamented songs sire more extrapair young (e.g., Hasselquist et al. 1996; Forstmeier et al. 2002). These patterns suggest that we may have under- rather than overestimated correlations between a male's repertoire size and total reproductive success on Mandarte. In summary, our data suggest that song repertoire size predicts the number of descendants (measured as grandrecruits) that a male song sparrow contributes to subsequent generations, an integrated measure of male fitness (Hunt et al. 2004). Or- 
Table 5: Estimated fitness parameters for male song sparrows with small, median, and large repertoires (5-6, 8, and 10-11 songs respectively) and for recruited offspring of these males

\begin{tabular}{|c|c|c|c|c|c|c|}
\hline \multirow{2}{*}{$\begin{array}{l}\text { Male's song } \\
\text { repertoire size }\end{array}$} & \multicolumn{3}{|c|}{ Male } & \multicolumn{3}{|c|}{$\begin{array}{l}\text { Males' recruited } \\
\text { offspring }\end{array}$} \\
\hline & $5-6$ & 8 & $10-11$ & $5-6$ & 8 & $10-11$ \\
\hline Longevity (years) & 2.4 & 3.3 & 4.2 & 3.0 & 3.3 & 3.6 \\
\hline Independent offspring & 4.0 & 7.9 & 11.8 & 6.7 & 7.9 & 9.1 \\
\hline Recruited offspring & 1.1 & 2.8 & 4.5 & 2.0 & 2.8 & 3.6 \\
\hline Grandindependents & 6.9 & 18.4 & 29.9 & & & \\
\hline Sons & & & & 8.8 & 18.4 & 28.0 \\
\hline Daughters & & & & 14.2 & 18.4 & 22.6 \\
\hline Grandrecruits & 2.5 & 6.0 & 9.5 & & & \\
\hline Sons & & & & 2.6 & 6.0 & 9.4 \\
\hline Daughters & & & & 5.2 & 6.0 & 6.8 \\
\hline
\end{tabular}

Note: Fitness was estimated for these representative categories using final models and assuming average year and cohort values for reproductive success and survival.

namentation has not to our knowledge been related to the number of descendants measured beyond a single generation in a free-living population, although more ornamented males left more local recruits in great tits (Parus major; McGregor et al. 1981; Lambrechts and Dhondt 1986), collared flycatchers (Ficedula albicollis; Gustafsson et al. 1995), and willow warblers (Phylloscopus trochilus; Gil and Slater 2000) and more recruits per fledgling in great reed warblers (Acrocephalus arundinaceus; Hasselquist 1998) and barn swallows (Hirundo rusticola; Møller 1994).

Phenotypic correlations between ornamentation and fitness can result from several underlying causes. Males with large repertoires may leave more descendants because they are themselves of higher phenotypic or genetic quality or because their female mates are higher quality or invest proportionately more in reproduction (Johnstone 1995; Cunningham and Russell 2000), although such differential female investment still implies underlying variation in male quality (Sheldon 2000). While these mechanisms are most reliably distinguished by experiment, major effects can be inferred from the life-history stages at which fitness variation arises. Female song sparrows mated to males with larger repertoires did not lay larger clutches. Although we could not test whether egg quality was adjusted, hatching success did not increase with male repertoire size. In song sparrows, incubation is undertaken entirely by females (Arcese et al. 2002), and hatching success is affected by female state; for example, hatching success varied with female age but not male age (table 3) and declines with maternal but not paternal inbreeding level (Keller 1998; Keller et al., forthcoming). These patterns suggest that the greater apparent fitness of males with large repertoires was not primarily attributable to correlated variation in female investment. Rather, these males left more descendants because they lived longer (and therefore bred more times) and successfully reared more hatched chicks to independence; male song sparrows usually contribute substantially to chick provisioning (Arcese et al. 2002). Our data therefore suggest that song repertoire size indicates a male song sparrow's quality in terms of reproductive value. On average, females are likely to gain immediate fitness benefits in terms of increased success in rearing offspring by pairing with males with large repertoires.

All measures of offspring fitness that we studied were to some degree positively correlated with paternal repertoire size. In particular, independent offspring of males with larger repertoires were more likely to recruit, and recruited offspring of males with larger repertoires tended to leave more independent and recruited grandoffspring than did recruited offspring of males with smaller repertoires. These trends were in most cases not statistically significant, although the correlation between paternal repertoire size and the number of grandrecruits left by recruited offspring remained robust after correcting for multiple tests. However, even relatively small effect sizes may be sufficient to drive sexual selection over evolutionary time, at least assuming a small cost of female choice (Alatalo et al. 1998). Very large sample sizes (>800) may be necessary to attach statistical significance to biologically significant effects in such cases (Jennions et al. 2001; Møller and Jennions 2001). Additionally, extrapair paternities may have introduced noise into the father-offspring relationships that we observed, although the impact of this uncertainty is difficult to assess without further knowledge of patterns of extrapair paternity and the relative influence of genetic and environmental factors on offspring fitness. Our data therefore suggest that female song sparrows pairing with males with large repertoires gain some fitness benefit in terms of increased reproductive value of offspring. We cannot distinguish whether this reflects an additive genetic component of fitness (a true "indirect" benefit of female choice) or long-term consequences of paternal effects on an offspring's natal environment.

Recent theories of sexual antagonism propose that the fitness consequences of mating with more ornamented males might differ between sons and daughters (Chippindale et al. 2001; Pizzari and Snook 2003). While experiments on laboratory populations have supported the hypothesis of sex-specific effects on offspring fitness (Chippindale et al. 2001; Fedorka and Mousseau 2004), there are few data from natural populations. In song sparrows, the relationship between paternal repertoire size and the number of grandoffspring left by recruited offspring tended to be stronger for sons than daughters (table 4). This tendency runs in the direction predicted by theories of sexual antagonism (Chippindale et al. 2001; Fedorka 
and Mousseau 2004). However, there was no evidence of similar sex-specific variation in offspring longevity or production of offspring (rather than grandoffspring). Further data are required to investigate these intriguing patterns in more detail.

The direction and magnitude of phenotypic correlations between ornamentation and fitness components have been suggested to indicate the evolutionary mechanism underlying sexual signaling (Andersson 1994; Møller and Alatalo 1999; Jennions et al. 2001). Pure Fisherian models predict a negative correlation between ornamentation and "viability," while positive correlations suggest quality- or condition-dependent indicator mechanisms (Andersson 1994; Jennions et al. 2001). In practice, however, a continuum of phenotypic correlations is possible (Kokko et al. 2002). Given this framework, knowledge of speciesspecific relationships between ornamentation and fitness can contribute to the comparative investigation of overarching investment patterns (Kokko et al. 2002, 2003). In song sparrows, the estimated effect size for the relationship between repertoire size and male longevity exceeded the average reported across previous studies relating ornamentation to male viability ( $r=0.43$ compared with unweighted and sample-size weighted means of 0.24 and 0.13; Jennions et al. 2001). In contrast, paternal repertoire size was a relatively weak predictor of offspring longevity ( $r \approx 0.13$ on average compared with unweighted and sample-size weighted means of 0.22 and 0.12 across previous studies of survival; Møller and Alatalo 1999). Similarly, estimated effect sizes typically were larger for measures of male fitness than average offspring fitness $(r=$ $0.38-0.57$ vs. $r=0.13-0.20$; fig. 1 ; table 4 ), although the effect size for sons' production of grandrecruits approached that for males ( $r=0.35$ vs. $r=0.39$ ). It is possible that extrapair paternities caused us to underestimate effect sizes for relationships between paternal repertoire size and measures of offspring fitness. However, in most cases, true effects could have equaled those observed for a male's own longevity and fitness only under relatively extreme scenarios, for example, if the most productive $20 \%$ of offspring assigned to males with small repertoires had all in fact been sired by males with large repertoires and vice versa. Current evidence therefore suggests that ornamentation generally explained a greater proportion of variation in male fitness than offspring fitness, opposite to the trend observed across the few other species where both effect sizes have been measured (Jennions et al. 2001). Using the number of recruited grandoffspring as the best fitness measure, we estimated the selection gradient for repertoire size as 0.24 (fig. 1 ).

The consistent positive correlations that we observecbetween repertoire size and fitness measures suggest that repertoire size is a condition-dependent trait in song spar- rows (Jennions et al. 2001). However, a song sparrow's repertoire size is unusual among condition-dependent ornaments in that it is finalized during a male's first few months of life and is an invariant characteristic of a breeding male (Cassidy 1993; Nordby et al. 2002). Other wellstudied condition-dependent ornaments vary, for example, with male age and physiological state (e.g., von Schantz et al. 1989; Hasselquist 1998; Hill et al. 2002). On Mandarte, a male song sparrow's total reproductive success is determined to a large extent by his longevity (Hochachka, forthcoming), but it is not clear what determines longevity. The correlations that we observed between repertoire size, longevity, and total reproductive success suggest that an individual's longevity (and therefore fitness) is determined early in life during the period of song learning. Repertoire size may therefore reflect some fixed aspect of male quality, such as genotype, or life-long consequences of natal conditions. Indeed, in song sparrows on Mandarte, 20\% of variation in song repertoire size is explained by a male's inbreeding level (and therefore relative heterozygosity; Reid et al. 2005). We could not include a male's inbreeding level in our analyses relating repertoire size to total reproductive success because currently there are few individuals for which all three parameters are known. Furthermore, song components have been shown to be permanently influenced by early developmental conditions in Melospiza sparrows and other passerines (Nowicki et al. 2002; Buchanan et al. 2003). The degree to which early developmental conditions affect both repertoire size and fitness, and the heritability of these traits, requires further investigation on Mandarte.

\section{Acknowledgments}

We thank the Tsawout and Tseycum First Nations bands for allowing us to work on Mandarte and the many researchers who collected data over the years. The long-term Mandarte project has received funding from the National Science and Engineering Research Council (Canada) and the National Science Foundation. J.M.R. was additionally funded by the Killam Foundation, the British Ecological Society, and Jesus College, Cambridge. H. Kokko, J. Madden, and two anonymous reviewers provided valuable comments on the manuscript. J.M.R. led the current analyses and writing; A.L.E.V.C., S.M.H., J.M.R., J.N.M.S., and P.K.S. recorded and analyzed songs; P.A. and J.N.M.S. oversaw stages of the long-term study; and L.F.K. and A.B.M. assisted with data collation.

\section{Literature Cited}

Alatalo, R. V., J. Kotiaho, J. Mappes, and S. Parri. 1998. Mate choice for offspring performance: major benefits or minor costs? Proceedings of the Royal Society of London B 265:2297-2301. 
Andersson, M. 1994. Sexual selection. Princeton University Press, Princeton, NJ.

$\rightarrow$ Arcese, P. 1987. Age, intrusion pressure and defence against floater $\rightarrow$ by territorial male song sparrows. Animal Behaviour 35:773-784.

$\rightarrow \longrightarrow$. 1989. Intrasexual competition, mating system and natal dispersal in song sparrows. Animal Behaviour 38:958-979.

$\rightarrow$ Arcese, P., J. N. M. Smith, W. M. Hochachka, C. M. Rogers, and D. Ludwig. 1992. Stability, regulation and the determination of abundance in an insular song sparrow population. Ecology 73:805-822 Arcese, P., M. K. Sogge, A. B. Marr, and M. A. Patten. 2002. Song sparrow (Melospiza melodia). In A. Poole and F. Gill, eds. The birds of North America. No. 704. The Birds of North America, Philadelphia.

$\rightarrow$ Brodie, E. D., III, A. J. Moore, and F. J. Janzen. 1995. Visualizing and quantifying natural selection. Trends in Ecology \& Evolution 10:313-318.

$\rightarrow$ Brommer, J. E., L. Gustafsson, H. Pietiäinen, and J. Merilä. 2004 Single-generation estimates of individual fitness as proxies for long-term genetic contribution. American Naturalist 163:505-517.

$\rightarrow$ Buchanan, K. L., K. A. Spencer, A. R. Goldsmith, and C. K. Catchpole. 2003. Song as an honest signal of past developmental stress in thr European starling (Sturnus vulgaris). Proceedings of the Royal Society of London B 270:1149-1156.

Cassidy, A. L. E. V. 1993. Song variation and learning in island populations of song sparrows. Ph.D. thesis. University of British Columbia.

$\rightarrow$ Catchpole, C. K. 1986. Song repertoires and reproductive success in the great reed warbler, Acrocephalus arundinaceus. Behavioral Ecology and Sociobiology 19:439-445.

$\rightarrow$ Chippindale, A. K., J. R. Gibson, and W. R. Rice. 2001. Negative genetic correlation for adult fitness reveals ontogenic conflict ir Drosophila. Proceedings of the National Academy of Sciences ot the USA 98:1671-1675.

$\rightarrow$ Cunningham, E. J. A., and A. F. Russell. 2000. Egg investment is influenced by male attractiveness in the mallard. Nature 404:7477.

Draper, N., and H. Smith. 1981. Applied regression analysis. Wiley, New York.

$\rightarrow$ Evans, M. R. 2003. Survival of male scarlet-tufted malachite sunbirds and the influence of ornamentation. Biological Journal of the Linnean Society 80:125-133.

Falconer, D. S., and T. F. C. Mackay. 1996. Introduction to quantitative genetics. Longman, London.

$\rightarrow$ Fedorka, K. M., and T. A. Mousseau. 2004. Female mating bias results in conflicting sex-specific offspring fitness. Nature 429:65-67.

$\rightarrow$ Forstmeier, W., B. Kempenaers, A. Meyer, and B. Leisler. 2002. A novel song parameter correlates with extra-pair paternity and reflects male longevity. Proceedings of the Royal Society of Londor B 269:1479-1485.

$\rightarrow$ Gil, D., and P. J. B. Slater. 2000. Multiple song repertoire characteristics in the willow warbler (Philoscopus trochilus): correlations witl female choice and offspring viability. Behavioral Ecology and Sociobiology 47:319-326.

$\rightarrow$ Gontard-Danek, M.-C., and A. P. Møller. 1999. The strength of sexua selection: a meta-analysis of bird studies. Behavioral Ecology 10: 476-486.

$\rightarrow$ Gustafsson, L., A. Qvarnström, and B. C. Sheldon. 1995. Trade-off $\rightarrow$ between life-history traits and a secondary sexual character in male collared flycatchers. Nature 375:311-313.

$\rightarrow$ Hasselquist, D. 1998. Polygyny in great reed warblers: a long-tern $\rightarrow$ Møller, A. P., and R. V. Alatalo. 1999. Good-genes effects in sexual study of factors contributing to male fitness. Ecology 79:23762390 .

Hasselquist, D., S. Bensch, and T. von Schantz. 1996. Correlation between male song repertoire, extra-pair paternity and offspring survival in the great reed warbler. Nature 381:229-232.

$\rightarrow$ Hiebert, S. M., P. K. Stoddard, and P. Arcese. 1989. Repertoire size, territory acquisition and reproductive success in the song sparrow. Animal Behaviour 37:266-273.

Hill, G. E., C. I. Inouye, and R. Montgomerie. 2002. Dietary carotenoids predict plumage coloration in wild house finches. Proceedings of the Royal Society of London B 269:1119-1124.

Hochachka, W. M. Forthcoming. Unequal lifetime reproductive success and its implication for small, isolated populations. In J. N. M. Smith, L. F. Keller, A. B. Marr, and P. Arcese, eds. Biology of small populations: the song sparrows of Mandarte Island. Oxford University Press, New York.

Höglund, J., and B. C. Sheldon. 1998. The cost of reproduction and sexual selection. Oikos 83:478-483.

Houston, A. I., and J. M. McNamara. 1999. Models of adaptive behaviour. Cambridge University Press, New York.

$\rightarrow$ Hunt, J., L. F. Bussière, M. D. Jennions, and R. Brooks. 2004. What is genetic quality? Trends in Ecology \& Evolution 19:329-333.

$\rightarrow$ Jennions, M. D., A. P. Møller, and M. Petrie. 2001. Sexually selected traits and adult survival: a meta-analysis. Quarterly Review of Biology 76:3-36.

$\rightarrow$ Johnstone, R. A. 1995. Sexual selection, honest advertisement and the handicap principle: reviewing the evidence. Biological Reviews 70:1-65.

$\rightarrow$ Joron, M., and P. M. Brakefield. 2003. Captivity masks inbreeding effects on male mating success in butterflies. Nature 424:191-194.

Keller, L. F. 1998. Inbreeding and its fitness effects in an insular population of song sparrows (Melospiza melodia). Evolution 52: 240-250. consequences of small population size: inbreeding and loss of genetic variation. In J. N. M. Smith, L. F. Keller, A. B. Marr, and P. Arcese, eds. Biology of small populations: the song sparrows of Mandarte Island. Oxford University Press, New York.

Koenig, W. D., D. Van Vuren, and P. N. Hooge. 1996. Detectability, philopatry and the distribution of dispersal distances in vertebrates. Trends in Ecology \& Evolution 11:514-517.

$\rightarrow$ Kokko, H. 1998. Should advertising parental care be honest? Proceedings of the Royal Society of London B 265:1871-1878.

Kokko, H., R. Brooks, J. M. McNamara, and A. I. Houston. 2002. The sexual selection continuum. Proceedings of the Royal Society of London B 269:1331-1340.

$\rightarrow$ Kokko, H., R. Brooks, M. Jennions, and J. Morley. 2003. The evolution of mate choice and mating biases. Proceedings of the Royal Society of London B 270:653-664.

$\rightarrow$ Lambrechts, M., and A. A. Dhondt. 1986. Male quality, reproduction and survival in the great tit (Parus major). Behavioral Ecology and Sociobiology 19:57-63.

$\rightarrow$ McGregor, P. K., J. R. Krebs, and C. M. Perrins. 1981. Song repertoires and lifetime reproductive success in the great tit (Parus major). American Naturalist 118:149-159.

Møller, A. P. 1994. Male ornament size as a reliable cue to enhanced offspring viability in the barn swallow. Proceedings of the National Academy of Sciences of the USA 91:6929-6932.
Keller, L. F., A. B. Marr, and J. M. Reid. Forthcoming. The genetic 
selection. Proceedings of the Royal Society of London B 266:8591.

$\rightarrow$ Møller, A. P., and M. D. Jennions. 2001. How important are direc fitness benefits of sexual selection? Naturwissenschaften 88:401415.

$\rightarrow$ Nordby, J. C., S. E. Campbell, and M. D. Beecher. 2002. Adult song sparrows do not alter their song repertoires. Ethology 108:39-50.

$\rightarrow$ Nowicki, S., W. A. Searcy, and S. Peters. 2002. Brain development, song learning and mate choice in birds: a review and experimental test of the "nutritional stress hypothesis." Journal of Comparative Physiology A 188:1003-1014.

$\rightarrow$ Perneger, T. V. 1998. What is wrong with Bonferroni adjustments. British Medical Journal 136:1236-1238.

$\rightarrow$ Pizzari, T., and R. R. Snook. 2003. Perspective: sexual conflict ana sexual selection: chasing away paradigm shifts. Evolution 57:12231236.

$\rightarrow$ Reid, J. M., P. Arcese, A. L. E. V. Cassidy, S. M. Hiebert, J. N. M. Smith, P. K. Stoddard, A. B. Marr, and L. F. Keller. 2004. Song repertoire size predicts initial mating success in male song sparrowc (Melospiza melodia). Animal Behaviour 68:1055-1063.

Reid, J. M., P. Arcese, A. L. E. V. Cassidy, J. N. M. Smith, A. B. Marr and L. F. Keller. 2005. Hamilton \& Zuk meet heterozygosity? song repertoire size indicates inbreeding and immunity in song sparrows (Melospiza melodia). Proceedings of the Royal Society of Londor B (forthcoming).

$\rightarrow$ Searcy, W. A., and P. Marler. 1981. A test for responsiveness to song structure and programming in female sparrows. Science 213:926928.

Searcy, W. A., and K. Yasukawa. 1996. Song and female choice. Pages 454-473 in D. E. Kroodsma and E. H. Miller, eds. Ecology and evolution of acoustic communication in birds. Cornell University Press, Ithaca, NY.

Searcy, W. A., P. D. McArthur, and K. Yasukawa. 1985. Song repertoire size and male quality in song sparrows. Condor 87:222-228.

$\rightarrow$ Searcy, W. A., S. Nowicki, and S. Peters. 1999. Song types as fundamental units in vocal repertoires. Animal Behaviour 58:37-44.

Sheldon, B. C. 2000. Differential allocation: tests, mechanisms and implications. Trends in Ecology \& Evolution 15:397-402.

Smith, J. N. M., L. F. Keller, A. B. Marr, and P. Arcese. Forthcoming. Biology of small populations: the song sparrows of Mandarte Island. Oxford University Press, New York.

Sokal, R. R., and F. J. Rohlf. 1995. Biometry. W. H. Freeman, New York.

$\rightarrow$ Stoddard, P. K., M. D Beecher, and M. Willis. 1988. Response of territorial male song sparrows to song types and variations. Behavioral Ecology and Sociobiology 22:125-130.

$\rightarrow$ von Schantz, T., G. Göransson, G. Andersson, I. Fröberg, M. Grahn, A. Helgée, and H. Wittzell. 1989. Female choice selects for a viability-based male trait in pheasants. Nature 337:166-169.

$\rightarrow$ Wedell, N., and T. Tregenza. 1999. Successful fathers sire successful sons. Evolution 53:620-625.

Wolfenbarger, L. L. 1999. Red coloration of male northern cardinals correlates with mate quality and territory quality. Behavioral Ecology 10:80-90.

$\rightarrow$ Zanette, L., J. N. M. Smith, H. van Oort, and M. Clinchy. 2003. Synergistic effects of food and predators on annual reproductive success in song sparrows. Proceedings of the Royal Society of London B 270:799-803.

Editor: Jonathan B. Losos Associate Editor: Ben C. Sheldon 